\title{
Convergence Behaviour of Growth Triangle: The Case of IMT-GT
}

\section{Dayang-Affizah $\mathbf{A M}^{1}$, Ramli $\mathbf{N}^{2 *}$ and Mee-Sing $\mathbf{T}^{1}$}

${ }^{1}$ Department of Economics, Faculty of Economics and Business, Universiti Malaysia Sarawak, 94300 Kota Samarahan, Sarawak, Malaysia

${ }^{2}$ Department of Economics, Faculty of Management and Economics, Sultan Idris Education University, 35900, Tanjong Malim, Perak, Malaysia

\begin{abstract}
Regional disparities and their evolution displayed a vital economic as well as political issue for most regions or countries (Blizkovsky, 2012). Due to realizing this shocking fact, it has drawn a lot of attention from all over the world to tackle this issue in order to avoid its adverse implication towards holistic economic development. The beauty of Indonesia-Malaysia-Thailand Growth Triangle (IMT-GT) is that it aims to increase the trade and investment among the three regions as it pursues private sector-led economic growth. However, evidence shows that the progress of development in this sub-region is either stagnant or slow. Hence, the aim of this study is to investigate the convergence hypothesis of the participating states and determine the reason behind each of the convergence behaviour portrayed. Non-linear time varying factor model namely Phillip and Sul has been employed in this study. The result implies that Negeri Sembilan is the only diverging group while the rest is converging. This phenomenon indicates that most of the states and provinces in this sub-region have positive performance towards the economic growth. Effective development planning can be done by policy makers after determining the performance of each of the states and provinces.
\end{abstract}

Keywords: Convergence; Income disparity; Regional inequalities

\section{Introduction}

Globalization generates massive interconnection between nationstates and societies through flows of resources such as products, money, people and information for the process of lessening territorial boundaries [1-3]. This creates the recent accelerating growth of economic regionalism or economic integration which has generated scholarly interest among the researchers. Economic convergence is a term originated from neoclassical era and has been studied broadly by the economists. In neoclassical growth theory, Solow [4] postulated that poor economies grow faster than rich ones if the economies are identical in terms of preferences and technology. Some researchers had done the study of convergence on different countries whereby some of them evolved a better model along the years. Barro and Sala-iMartin [5] for instance, had documented the measure of the non-linear relation between initial output and growth. The setup is developed for neoclassical growth models which is used to measure club convergence as well. Upon realizing the fact that economic convergence among states can aid the performance of the economic growth, regionalism is created by state authorities. During this period, globalization tends to minimise the boundaries to invent a larger space out of smaller territorial spaces bounded in nation-states [6]. In the early 1990s, some regional economic institutions are born like European Union (EU), North America Free Trade Agreement (NAFTA), Mercusor and Asia-Pacific Economic Cooperation (APEC). All of these institutions are established with one main goal which is to enhance the economic growth by implementing policies such as free trade area for their region accordingly. Different country, language, politics or cultures are not the obstacles for them to create a single market as mutual agreement will be made among them.

A region is generally often defined as a group of countries located in the same geographically specified area. Although the group of regionalization is big and wide, some authorities suggested that a smaller regional cooperation would be better as it will be easier to be monitored by them. Due to this concept, smaller economic regionalism namely growth triangle was proposed under Association of Southeast Asian Nations (ASEAN). This term is a commonlyheard cross-border economic zone that is established for better and more specific development of the participating regions. Jitpiromsri et al. [7] and Waldron [8] declared that growth triangle is conceptually involves the attempt to create a superb sub-regional economic zone with geographical proximity, economically disparate regions which is separated by their common obstacles to become economically linked by intense cross-border investments and other economic development activities.

IMT-GT which stands for Indonesia, Malaysia and Thailand Growth Triangle is a sub-region cooperation initiative formerly proposed by Malaysian fourth Prime Minister Tun Dr Mahathir. This joint cooperation is established in 1993 with the motivation to pull the comparative advantage to the higher level as Asian Development Bank's (ADB) major conceptual framework is to identify the potential business opportunities as well as the principal constraints of the projects. As this cooperation is private sector-led economy, their dynamic aim of this project is to increase the trade and investment in the sub-region of the three participating countries by increasing their exports out. IMT-GT is one of the sub-regions formed under ASEAN has intense connection to ASEAN economically. ASEAN has $32.1 \%$ share of cumulative trade over the years of 2008 until 2011 (IMT-GT, 2013). This has shown that inter-region in ASEAN occurred, which greatly contributed in the trade share of this sub-region.

However, the major issue that is widely debated nowadays is the matter of regional disparity among the participating states and provinces in IMT-GT. East Asia Analytical Unit (1995) of Australia described IMT-GT would face a big challenge which is to endure a balance distribution of benefits among the participating states and provinces. Mid-term Review (MTR) of the IMT-GT Roadmap

*Corresponding author: Ramli N, Department of Economics, Faculty of Managemen and Economics, Sultan Idris Education University, 35900, Tanjong Malim, Perak Malaysia, Tel: 05-4506000; E-mail: norimah@fpe.upsi.edu.my

Received March 09, 2016; Accepted March 25, 2016; Published April 02, 2016

Citation: Dayang-Affizah AM, Ramli N, Mee-Sing T (2016) Convergence Behaviour of Growth Triangle: The Case of IMT-GT. Bus Eco J 7: 205. doi:10.4172/21516219.1000205

Copyright: (c) 2016 Dayang-Affizah AM, et al. This is an open-access article distributed under the terms of the Creative Commons Attribution License, which permits unrestricted use, distribution, and reproduction in any medium, provided the original author and source are credited. 
for Development 2007-2011 on the other hand, has stated that the economic growth of this cooperation has been either static or slow. In this report, it also mentioned that Roadmap for Development 20072011 has a weak connection between the strategic thrusts and the current projects which in turn cause the goals cannot be achieved. The closure of inequality is vital as it may hinder poverty reduction and also misallocation of human capital [9]. This is to ensure the realization of ASEAN Economic Community (AEC) is achieved. As such, this paper is to assess empirically the possible cluster or club convergence within the same path of economic growth.

\section{Literature Review}

East Asia Analytical Unit [10] claimed that Indonesia-MalaysiaThailand Growth Triangle is born to yield intra-regional trade and investment due to the recognition of benefits like factor endowments and natural resource complementarities. There is some research which supports this report that this growth triangle can bring intra-regional benefits in terms of complementarities as well as factor endowments. One of the studies was done by Ibrahim et al. [11] regarding the benefits and problems of the concept of IMT-GT. In this study, the researchers discovered that there are still many golden opportunities for development which are in line with the Asian Development Bank (ADB) report. They suggested that detailed promotion programs should be organized in order to announce the concept, benefits and purpose of this organization for the people in the sub-regions. Besides that, they also suggested that the secretariat to provide more information regarding the principles and framework of the concept so that the degree of cooperation between companies can be increased as well as minimize the problems and obstacles they faced.

There are several studies that have been done by researchers about intra-regional convergence of certain regions, countries or states. Barossi-Filho and Azzoni [12] are one of the researchers that have investigated the pattern of intra-regional convergence of Brazil. The result in this study showed that there is a sign of stochastic convergence among the regions. They also noticed that convergence within the region is not homogenous and this can help them identify which regions and states are contributing to convergence and vice versa. Costa and Iezzi [13] and Terrasi [14] investigated the existence of economic intra-regional convergence and the pattern of convergence in Italy by utilizing the GDP, gross fixed investment and units of labour as their variables. In their findings, they discovered that there is economic convergence process for the Italian regions within the time period of 1984 to 1996 . They also analysed that the technological innovation plays a relevant role for regional development.

In addition, there are several studies regarding the inter-regional convergence in certain regions or countries. Miller and Grene [15] applied beta convergence techniques onto cross sectional per capita income data of US regions to investigate whether the regions are converging over time period covering 1969 to 1997 . They realized that there is continuous convergence behaviour occurred for economic regions of the US in time period from 1969 to 1997. In their study, they also realized the problem of spatial correlation of error terms in regressions. However, they predicted that regional autocorrelation is worse in convergence regressions of data sets of political regions than it is in those for economic regions. Aubyn [16] conducted a research to examine the existence of inter-regional convergence across industrialized countries. The author used the time series data from 1890 to 1989. By using the ADF method and Kalman filter method, the author found that there is a favoring convergence across
16 industrialized countries. The countries are Australia, Austria, Belgium, Canada, Denmark, Finland, France, Germany, Italy, Japan, the Netherland, Norway, Sweden, Switzerland, the UK and USA.

On the other hand, Lim and McAleer [17] have conducted a research study on convergence in terms of inter and intra-regional trend of ASEAN-5 (Malaysia, Indonesia, Thailand, Singapore and Philippines) and USA. They found that the overall pattern seems to indicate a slight reduction in the standard deviation over time. Apart from this, they also examined the effect of technological catching up for ASEAN-5 and they realized that the backward country with low initial income and productivity tend to grow more rapidly by copying the technology from leader country. They also found out that there is no evidence to support income convergence between pairs of ASEAN-5 countries. Besides that, the empirical finding also shows that there is no evidence of catching up by ASEAN-5 to the technology leader with the exception of Singapore.

Chakravorty [18] is one of the researchers who done on both way of convergence on finding whether the industrial investment will be determined by the convergence pattern of India. The researcher discovered that districts with earlier success continued to receive new investment. Geographical factor has greatly determined the investment flow. India has also experienced inter-regional polarization of industry as well as intra-regional dispersal in the leading region. Not only that, Fujita and $\mathrm{Hu}$ [19] carried out a research on discovering the regional disparity in China. From the result, they found out that the income inequality among the coastal area and interior had been escalating (inter-regional divergence). There was a trend of intra-regional convergence within the coastal provinces. They understood that globalization and economic liberalization has significant impact on the increasing regional disparity.

\section{Data and Econometric Methodology}

\section{Data description}

The annually time series data are collected for the period from 1999-2013. The real gross domestic product (GDP) per capita for each of the participating provinces in IMT-GT in current 2010 prices is utilized in this study. These provinces are 14 provinces in Southern Thailand, eight states of Peninsular Malaysia and 10 provinces in the island of Sumatra in Indonesia. The 14 provinces in Southern Thailand are Krabi, Nakhon Si Thammarat, Narathiwat, Pattani, Phattalung, Satun, Songkhla, Trang, Yala, Chumphon, Ranong, Surat Thani, Phang Nga and Phuket. As for the eight states of Peninsular Malaysia are Kedah, Kelantan, Melaka, Negeri Sembilan, Penang, Perak, Perlis and Selangor. Sumatra in Indonesia includes Aceh, Bangka-Belitung, Bengkulu, Jambi, Lampung, North Sumatra, Riau, Riau Islands, South Sumatra and West Sumatra. However, Riau Island is excluded in the analysis as the data could not be obtained. Data for states ${ }^{\text {ee }}$ GDP per capita at constant price are compiled from the department of statistics of Malaysia (DOS), National Economic and Social Development Board of Thailand as well as Central Bureau of Statistics of Indonesia. Interpolation is taken onto a complete range of time-series data for provinces GDP per capita using information on time, time-squared, time-cubed and lagged one-period Indonesia's per capita GDP. In this study, the non-linear time varying factor model are employed to examine the possibility of the existence of multiple equilibriums.

\section{Phillip and Sul (2007)}

Phillip and Sul [2] have proposed a better econometric approach to analyse the transitional behaviour of per capita income among 
IMT-GT's states and provinces over the 1999-2013 period. In other words it is to test the convergence hypothesis and the identification of convergence clubs. Their method uses a nonlinear time-varying factor model and provides the framework for modelling transitional dynamics as well as long run behaviour.

Usually, panel data are decomposed in the following method:

$$
\log y_{i t}=\varphi_{i} \mu_{t}+\varepsilon_{i t}
$$

where is $\varphi_{i}$ the unit characteristic component, $\mu_{t}$ the common factor and $\varepsilon_{i t}$ the error term. In contrast, in the specification applied here, log of income per capita, $\log y_{i t}$, has a time varying factor representation that can be derived from the conventional panel data representation:

$$
\log y_{i t}=\left(\varphi_{i}+\frac{\varepsilon_{i t}}{\mu_{i t}}\right) \mu_{i t}=\delta_{i t} \mu_{i t}
$$

Where $\delta_{i t}$ absorbs the error term and the unit specific component and thus represents the idiosyncratic part that is varying over time. The second approach seeks to describe income per capita by measuring the share $\left(\delta_{i t}\right)$ of the common growth path $\left(\mu_{t}\right)$ that economy undergoes. A relative transition coefficient $h_{i t}$ is constructed to model the transition coefficients:

$$
h_{i t}=\frac{\log y_{i t}}{\frac{1}{N} \sum_{i=1}^{N} \log y_{i t}}=\frac{\delta_{i t}}{\frac{1}{N} \sum_{i=1}^{N} \delta_{i t}}
$$

such that the common growth path is eliminated. Thus $h_{i t}$ symbolized the transition path of the economy $i$ relative to the cross-section average and has a twofold interpretation. Firstly, it measures the individual behaviour in relation to other economies and secondly, it describes the relative departures of the economy $i$ from the common growth path $\mu_{t}$. In this framework, all $\mathrm{N}$ economies will converge, at some point in the future, $h_{i t} \rightarrow 1$ for all $i$ as $t \rightarrow \infty$. Then the crosssectional variance of $h_{i t}$, denoted by $v_{t}^{2}=\frac{1}{N} \sum\left(\mathrm{h}_{\mathrm{it}}-1\right)^{2} \sum$, converges to zero. In order to specify the hypothesis of convergence, further steps have been taken. Phillip and Sul [2] model $\delta_{i t}$ in a semi-parametric form as shown below:

$$
\delta_{i t}=\delta_{i}+\frac{\sigma_{i} \xi_{i t}}{L(t) t^{\alpha}}
$$

Where $\delta_{i t}$ is fixed, $\sigma_{\mathrm{i}}$ is an idiosyncratic scale parameter ${ }^{3}, \xi_{i t}$ is iid $(0,1), \mathrm{L}(\mathrm{t})$ is a slowly varying function and $\alpha$ is the decay rate. The null hypothesis of convergence for all $i$, can be written as:

$$
H_{0}: \delta_{i}=\delta, \alpha \geq 0
$$

while the alternative hypothesis of non-convergence for some, $i$ can be written as

$$
H_{A}: \delta_{i} \neq \delta, \alpha<0
$$

To test for convergence, Phillip and Sul [2] have suggested the following regression:

$$
\log \frac{H_{1}}{H_{t}}-2 \log L(t)=\alpha+b \log t+\mu_{t}
$$

For $\mathrm{t}=[\mathrm{rT}],[\mathrm{rT}]+1, \ldots, \mathrm{T}$, and $\mathrm{r}>0$. They also suggested that we can test for convergence hypothesis by a $t$ test of the inequality, $\alpha \geq 0$. They called it the one-sided $t$ test which is based on $t$, the $\log t$ test due to the presence of the log $t$ regressor in Equation 7.

\section{Empirical Findings}

\section{Full panel convergence}

The panel convergence analysis on aggregate level is employed on the 31 states and provinces of real per capita GDP by using the log t test. Table 1 reports the results of the panel convergence methodology for real per capita GDP of 31 states and provinces. After determining the ranking of the states according to their last-period value of the data, panel convergence is analysed for acknowledging the level of convergence in aggregate level (Table 1).

As this method is based on non-linear time varying factor, the data does not need to run stationary data as this method able to cater the problem of stationarity of the sample data. The first row shows the result of testing full convergence (i. e, divergence among all sample states and provinces. The magnitude of the convergence coefficient, $\hat{b}$, delineates the speed of convergence. If the value of $\hat{b}$ is typically high, it indicates that there is a faster rate of convergence. In this study, the $\mathrm{t}$-statistic is employed to determine the convergence or divergence of the states and provinces. The results show divergence with -21.10395 which also indicates the rejection of the null hypothesis of convergence at the $5 \%$ significance level. The null hypothesis of full convergence is rejected for the period of 2003 to 2013 when data trimming focuses on the latter part of the sample data. This is because Phillip and Sul [1] believed that the empirical log t regression is based on time series data where the first $r \%(0.3)$ of the data is removed before analysis.

According to this analysis, the speed of convergence is not fast enough to ensure cointegrated behaviour. This vividly shows that overall the states and provinces of IMT GT are heterogeneous in terms of real GDP per capita. However, this does not imply that there is no convergence in the sub group of the states and provinces, which brings a further analysis for the trimmed observation. As stated by Phillip and Sul (2007) although cointegration and convergence are highly related, they have distinct features and cointegration tests do not serve as an adequate test for further convergence test. They also believed that there will be many possibilities exist if the null hypothesis of full panel convergence is removed. Therefore, the method formed by Phillip and Sul (2007) is adapted for the next section.

\section{Cross-sectional variation}

According to Philip and Sul [2], they stated that cross sectional variation is needed to examine the overall convergence of transition parameters, it. The formula for this method is designed to measure the loading coefficient $\delta_{i t}$ in relation to the panel average at time $t$. This concept is applicable in the analysis of growth convergence and to measure transition effects. The decreasing cross sectional variation does not directly imply overall convergence as there might be local convergence within subgroups and overall divergence (Figure 1).

Figure 1 displays the cross sectional variation of the 31 states and provinces in IMT GT within the period of 2003-2013. In order to avoid the initial effect of the base year initialization, the first four yearly

\begin{tabular}{|l|l|l|}
\hline Clubs & States & t- statistic \\
\hline Full Sample & 31 states and provinces of IMT GT & $-21.10395^{* *}$ \\
\hline
\end{tabular}

Table 1: Panel convergence (Per Capita GDP). 

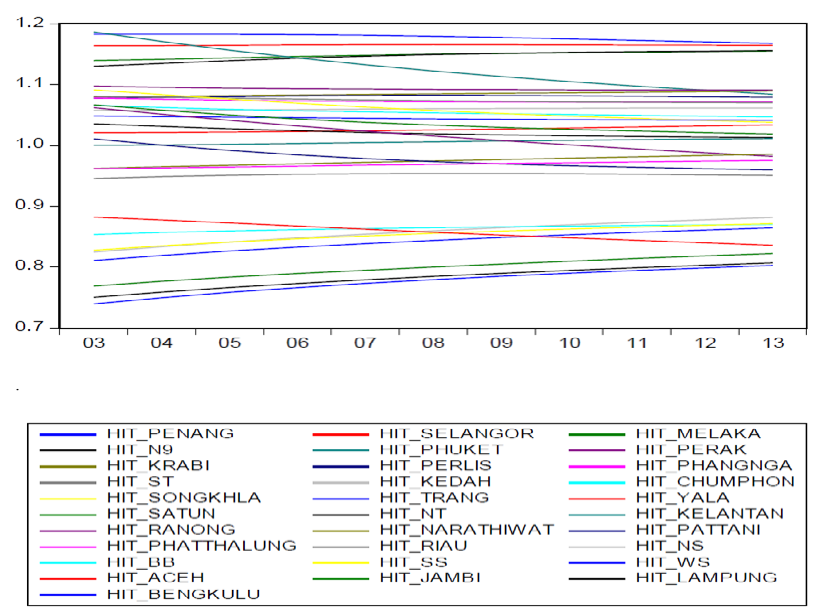

Figure 1: Cross-sectional Variation of the 31 States and Provinces.

observations is discarded and 11 filtered observations are used in the following analysis. The relative transition parameters for this period are smoothening by employing the Whittaker-Hodrick- Prescott (WHP) smoothing filter. This technical mechanism is commonly used to separate the cyclical component of a time series from raw data.

\section{Club clustering and convergence}

The formation of the seven different convergence clubs conforms to the results of the related literature. Seven clusters of convergence symbolize the weak convergence among them which also indicates strong dissimilarity in its economic structure as a whole. According to Phillip and Sul [2], this procedure can be divided into 2 simpler steps which are similar and repeated. At this stage, the base country is selected according to the highest rank (Penang) and the log t test is employed to create a core group. The states and provinces selection ranking is based on the last year observation of the data. Penang is chosen to be the core among all as it has the highest real GDP per capita if compare to the other states. After that, the remaining states and provinces are added separately to the core group to test for the convergence hypothesis. If the $\mathrm{t}$-statistic is smaller than the critical value $(-1.65)$ then the subgroup is finished and the procedure is repeated again to form a new subgroup.

According to Table 2, the results suggests that convergence exists across most of the states in this sub-region which are the first club; Penang (core), Selangor, Melaka, the third club; Phuket, Perak, Krabi, Perlis, Phangnga, the fourth club which are Surat Thani and Kedah, the fifth club; Chumphon, Songkhla, Trang, Yala, Satun, Nakhon Si Tammarat, Kelantan, Ranong, the sixth club; Narathiwat, Pattani, Phatthalung, Riau, North Sumatera, and the last club which are Bangka Belitung, South Sumatera, West Sumatera, Aceh, Jambi, Lampung and Bengkulu. This determined by comparing the t-statistic given in the result with the critical value. Since the value of $t$-statistic is greater than the critical value which is -1.65 then it is consider as converging. Negeri Sembilan is the only outlier as determined by the value of $t$-statistic $(-27.16206)$ is smaller than -1.65 , thus it is consider as diverging from the core clubs (Table 2).

Interestingly, the results display clearly that Negeri Sembilan is the only diverging states in IMT-GT. This is a contradiction to most of the statistical data whereby it stated that Negeri Sembilan is not the least contributor in GDP for the participating states in Malaysia-
GT. In Figure 2, the graph displays clearly that Perlis has the least percentage share in Malaysia-GT's GDP in 2009 and 2013. According to Department of Statistics of Malaysia (DOS), Negeri Sembilan holds the share of $3.8 \%$ as well as $3.6 \%$ in the share of nation's GDP in 2009 and 2013 respectively. As for Perlis only holds less than one percent of share in both years. Midterm Review of IMT-GT has stated that the growth in the IMT-GT provinces was similar to those at the national levels (Figure 2).

However, it does show a slight drop in the percentage share in 2013 for Negeri Sembilan which might be the cause for the diverging behaviour displayed in the analysis. IMT-GT has established a working group namely Working Group Action Plans in 2009 to review the development projects held in each region. According to this team, lack of activities at completed IMT-GT plaza is a cause of concern. Private sector participation is one of the factors to this issue as lack of support from them will deteriorate the growth of development projects established in this sub-region. This can be proven by the study regarding the awareness of the concept of IMT-GT conducted by Ibrahim et al. [11]. In their study, they found out that the degree of cooperation between the private companies within the region is minimal which is only $10.2 \%$ of respondents are involved in the business venture under IMT-GT. Besides that, in 2009, Negeri Sembilan state government proposes the project of establishing IMT Plaza to be dropped from Working Group on Trade and Investment (WGTI). In addition, there has yet an infrastructure development planning to be established in this state. Due to the lack of improvement in infrastructure, it will drive a cumulative process of regional divergence [20].

On the other hand, although Perlis has the lowest share in GDP, it shows a steady state growth in those years. This might be due to the development projects under IMT-GT been ravished in that state such as Development of Border Township at Padang Besar, Perlis as well as Perlis Halal Park. The same thing goes to the other participating states which show a slight increase in their percentage shares. Development projects, for instance connectivity corridors (CC) may be the reason of the converging behaviour in other states and provinces. By looking at the ranking of GDP per capita, although Bengkulu appears to be in the lowest rank, its performance seems to be encouraging. This might be due to one of the development project which is ASEAN Highway route 151 Bengkulu-Lubuk Linggau-Lahat.

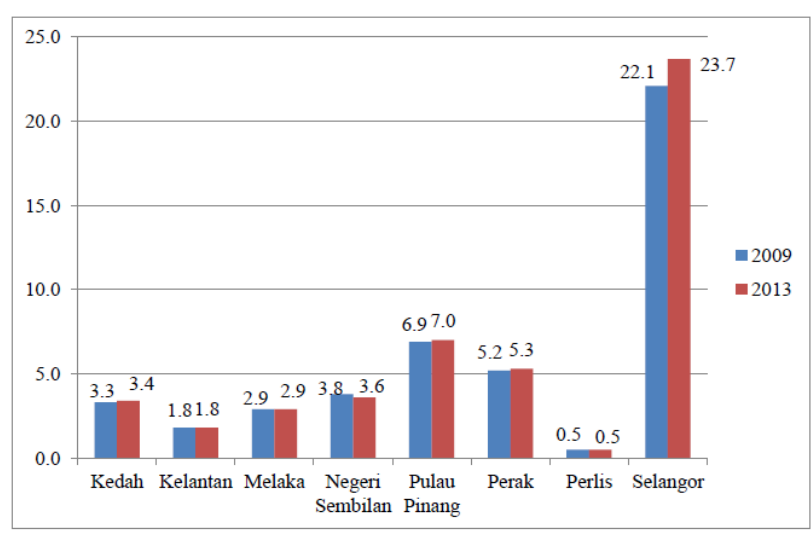

Source: Department of Statistics, Malaysin

Figure 2: Percentage Share of GDP for the Participating States in Malaysia (2009 and 2013, \%). 
Citation: Dayang-Affizah AM, Ramli N, Mee-Sing T (2016) Convergence Behaviour of Growth Triangle: The Case of IMT-GT. Bus Eco J 7: 205. doi:10.4172/2151-6219.1000205

Page 5 of 6

\begin{tabular}{|c|c|c|c|c|c|c|c|c|c|}
\hline $\begin{array}{l}\text { Last T } \\
\text { order }\end{array}$ & States & Step 1 & Step 2 & Step 1 & Step 2 & Step 1 & Step 2 & Club & Remarks \\
\hline 1 & Penang & Base & Core & & & & & 1 & Convergence \\
\hline 2 & Selangor & 2.389571 & & & & & & 1 & Convergence \\
\hline 3 & Melaka & 2.901403 & & & & & & 1 & Convergence \\
\hline 4 & Negeri Sembilan & -22.03781 & Outlier & & & & & 2 & Divergence \\
\hline 5 & Phuket & & -27.16206 & Base & & & & 3 & Divergence \\
\hline 6 & Perak & & 3.499645 & & & & & 3 & Convergence \\
\hline 7 & Krabi & & 4.498835 & & & & & 3 & Convergence \\
\hline 8 & Perlis & & 5.974086 & & & & & 3 & Convergence \\
\hline 9 & Phangnga & & 7.597905 & & & & & 3 & Convergence \\
\hline 10 & Surat Thani & & -31.98413 & Base & & & & 4 & Divergence \\
\hline 11 & Kedah & & & 6.885318 & & & & 4 & Convergenc \\
\hline 12 & Chumphon & & & -4.466062 & Base & & & 5 & Convergence \\
\hline 13 & Songkhla & & & & 1.567235 & & & 5 & Convergence \\
\hline 14 & Trang & & & & 5.802446 & & & 5 & Convergence \\
\hline 15 & Yala & & & & 7.847699 & & & 5 & Convergence \\
\hline 16 & Satun & & & & 9.319855 & & & 5 & Convergence \\
\hline 17 & $\begin{array}{l}\text { Nakhon Si } \\
\text { Tammarat }\end{array}$ & & & & 8.595061 & & & 5 & Convergence \\
\hline 18 & Kelantan & & & & 9.371126 & & & 5 & Convergence \\
\hline 19 & Ranong & & & & 3.461366 & & & 5 & Convergence \\
\hline 20 & Narathiwat & & & & -2.515913 & Base & & 6 & Divergence \\
\hline 21 & Pattani & & & & & 0.416020 & & 6 & Convergence \\
\hline 22 & Phatthalung & & & & & 0.678924 & & 6 & Convergence \\
\hline 23 & Riau & & & & & 0.754068 & & 6 & Convergence \\
\hline 24 & North Sumatera & & & & & 2.065646 & & 6 & Convergence \\
\hline 25 & Bangka Belitung & & & & & -2.932166 & Base & 7 & Convergence \\
\hline 26 & South Sumatera & & & & & & 4.328734 & 7 & Convergence \\
\hline 27 & West Sumatera & & & & & & 5.693916 & 7 & Convergence \\
\hline 28 & Aceh & & & & & & 2.281783 & 7 & Convergence \\
\hline 29 & Jambi & & & & & & 2.312015 & 7 & Convergence \\
\hline 30 & Lampung & & & & & & 8.382605 & 7 & Convergence \\
\hline 31 & Bengkulu & & & & & & 6.874503 & 7 & Convergence \\
\hline
\end{tabular}

Table 2: Results of convergence clubs in GDP per capita.

\section{Conclusion}

The analysis on the aggregate level of the 31 states and provinces has displayed a divergent behaviour. This has been contradicted to the overall economic growth of this organisation which directly affects the economic growth of the participating countries. For simplicity, Phillip and Sul [2] $\log t$ test has been employed in this study to analyse the possibility of the convergence behaviour exist in the data selected. After the formation of clusters of states and by using Penang (the highest last observation) as the benchmark state, the result shows that the states can be classified into seven different groups. In this analysis, the result displayed an interesting fact that Negeri Sembilan is the only outlier with the core group. This might be due to the lack of development project especially in terms of infrastructure imposed in this state. Krugman [20] mentioned that lack of improvement in infrastructure will cause a cumulative process of regional divergence.

As for the other participating states and provinces, the analysis proved that they are showing convergence behaviour towards their core group. The reason to this performance might be the consistent development projects implanted in these states and provinces. These projects can boost their economic performance as well as create the spillover effects to other neighbouring states and provinces. By realising the convergence behaviour of each of the participating states and provinces, relevant policy can be implemented according to the states and provinces need. For example, implementation of a policy regarding infrastructure development in Negeri Sembilan might drive more economic growth. Furthermore, the strength of Negeri Sembilan in terms of economic sectors should be enhanced for a faster and greater effect on its development. Negeri Sembilan which has beautiful beach scenery and other attracting places can be more focus on ecotourism and culture tourism.

Related authorities should encourage more trade and investment in IMT-GT as its main goal is to boost the economic growth of participating states and provinces through integration. In this corporation, private sector plays vital role in cooperating with the 
government to inject more investment in order to create intra as well as inter-trade and investment especially those diverging states. For instance, Asian Development Bank (ADB) is commencing special border economic zones (SBEZ) in this sub-region as this project could really improve inter-regional cooperation among its member countries [21]. This project is believed to be able to promote cross-border trade and investment which can encourage more economic and social development along the border between countries.

Upon realising the clusters or groups of states and provinces in this study, suitable policy can be visualised clearly for the authorities. The first group which consists of Penang, Melaka and Selangor has the comparative advantage in terms of industrialisation, can be enhanced through establishing Halal Hub. Integration takes place here as generating halal business enable to create more opportunities for participating states and provinces in Indonesia and Thailand. As the third, fourth and fifth group are bestowed with agricultural and fisheries activities, they can integrate with the first group by supplying halal food for the industries to generate more halal business. Effective research and development on improving agriculture and fishery sector should be created.

Since Satun is in the fifth cluster, it can aid this sub-regional cooperation by providing cross-border transportation from Thailand to Malaysia through ferry. As for Nakhon Si Tammarat, education institutions lie in this province which can give the comparative advantage of offering better education for neighbouring countries especially Indonesia and Malaysia. Producing a better quality of students can provide skilled employees for many kinds of industry. Programmes like exchanging students and visiting delegates can improve the momentum of closer relationship among countries in IMT-GT as well as inter-changing types of information of one country to another. Moreover, small and medium-sized industry (SME) can be emphasized for states and provinces in sixth and seventh group. Providing more benefits for SMEs can motivate the locals to improve their business which can aid in boosting intra or inter-trade and investment. For instance, Phatthalung can produce coconut toffee and Bangka Belitung can emphasise on producing white pepper for other states or countries. Agro and eco-tourism in Jambi, West Sumatera, Riau and Aceh can be enhanced by promoting their tourist attraction destinations.

\section{References}

1. Indonesia-Malaysia-Thailand Growth Triangle (2013) IMT-GT at a Glance: A statistical information brief. (Brochure). Putrajaya, Malaysia.

2. Phillips PCB, Sul D (2007) Transition modeling and econometric convergence tests. Econometrica 75: 1771-1855.
3. Hurrell A (1995) Regionalism in Theoretical Perspective. In: Fawcett L, Hurrel Al (Eds). Regionalism in World Politic. Oxford University Press: Oxford, United Kingdom pp: 36-73.

4. Solow R (1956) A contribution to the theory of economic growth. Q J Econ 70 65-94.

5. Barro RJ, Sala-i-Martin X (2004) Economic Growth. MIT Press: Cambridge.

6. Nesadurai H (2002) Globalisation and Economic Regionalism: A Survey and Critique of the Literature. Centre for the Study of Globalisation and Regionalisation (CSGR) Working Paper No. 108/02.

7. Jitpiromsri S, Kitthaworn P, Rahimmula C (2000) The Indonesia-MalaysiaThailand Growth Triangle (IMT-GT) project: Implications of "Open Regionalism" to the local economy. Songklanakarin Journal of Social Science \& Humanities, 6: $40-48$.

8. Waldron DG (1997) Growth triangle: A Strategic Assessment. Multinational Business Review.

9. Asian Development Bank (2012) Asian Development Outlook 2012. Confronting rising inequality in Asia. Phillipines.

10. East Asia Analytical Unit (1995) Growth triangle of Southeast Asia. The National Library of Australia: Australia.

11. Ibrahim FW, Samidi AM, Hassan S, Karim NAA (2002) Awareness of private sector of the IMT-GT concept: benefits and problems. Analisis 9: 15-30.

12. Barossi-Filho M, Azzoni CR (2003) A time series analysis of regional income convergence in Brazil. Fortaleza.

13. Costa M, lezzi S (2004) Technology spillover and regional convergence process: a statistical analysis of the Italian case. Statistical Methods and Applications 13: 375-398.

14. Terrasi M (1999) Convergence and divergence across Italian regions. Annals of Regional Science 33: 491-510.

15. Miller JR, Gene I (2005) Alternative regional specification and convergence of US regional growth rates. Annals of Regional Science 39: 241-252.

16. Aubyn MS (1999) Convergence across industrialised countries (1980-1989): new results using time series methods. Empirical Economics 24: 23-44.

17. Lim LK, McAleer M (2000) Convergence and catching up in South East Asia a comparative analysis. Econometric Society and World Congress 2000 Contributed Paper, Econometric Society.

18. Chakravorty S (2003) Industrial location in post-reform India: patterns of inter-regional divergence and intra-regional convergence. The Journal of Development Studies 40: 120-152.

19. Fujita M, Hu D (2001) Regional disparity in China 1985-1994: the effects of globalization and economic liberalization. Annals of Regional Science 35: 3-37.

20. Krugman P (1991) Geography and trade. The MIT Press: United States of America.

21. Bernama (2013) ADB to begin a study on IMT-GT Border Economic Zone. New Sarawak Tribune. 